\title{
Metabolic Activity during the Degenerative and Early Regenerative Stages of Minced Skeletal Muscle 1,2
}

\author{
MIKEL H. SNOW ${ }^{3}$ \\ Department of Anatomy, University of Michigan, Ann Arbor, Michigan
}

\begin{abstract}
In the rat, autotransplanted minced skeletal muscle undergoes degenerative changes prior to the regeneration of a whole muscle. In this study, both the degenerative and early regenerative processes were examined using histochemical procedures for the localization of glycogen, neutral lipid, phosphorylase, lactate dehydrogenase, cytochrome oxidase, glucose-6-phosphate dehydrogenase and non-specific esterases. Glycogen and phosphorylase activity disappeared in all muscle fibers within 24 hours after mincing. Vascular injections of ink demonstrated that during the second to tenth days after mincing a central ischemic zone of degenerating minced muscle was surrounded by a vascularized zone of regenerating muscle. Lactate dehydrogenase staining persisted during the first week in the degenerating muscle fragments of the central zone. This latter histochemical observation was supported by quantitative evidence which showed that degenerating muscle isolated from the central zone of four day regenerates produced lactic acid in the presence of glucose. Cytochrome oxidase activity decreased rapidly in the degenerating muscle while succinic dehydrogenase persisted somewhat longer. Although non-specific esterases and glucose-6-phosphate dehydrogenase activities were not significant in normal muscle, they were histochemically detectable in degenerating muscle during the first week. The capacity for anaerobic metabolism apparently persists in the degenerating minced muscle for several days; this energy source may be sufficient to maintain the myogenic cells in an environment of degeneration and ischemia until they become reassociated with a vascular supply.
\end{abstract}

Regeneration of skeletal muscle involves both pathological and developmental processes since muscle injury and degeneration precede the histological appearance of myogenic cells, but we do not know to what extent the degenerating tissue contributes to the successful restoration of new muscle fibers. While previous studies have described the morphological changes associated with regeneration of damaged muscle (reviewed by Field, '60; Betz et al., '66; Schmidt, '68), only a few investigations have been concerned with biochemical and metabolic changes (reviewed by Schmidt, '68 and Carlson, '72).

The present investigation examined certain aspects of the metabolic activity during skeletal muscle regeneration and attempted to relate this activity to structural changes. Aerobic and anaerobic metabolic pathways were surveyed by employing histochemical procedures to detect and localize indicator enzyme reactions. These procedures were applied to regeneration of minced muscle (Studitsky et al., '56; Carlson, '68), a system which is particularly well suited for metabolic study because it provides a large mass of tissue in which all fibers are uniformly injured, and in which the early regenerates contain degenerating and regenerating muscle in distinct zones which can be surgically separated and examined independently.

The results demonstrate a persistence of anaerobic metabolism in the ischemic central zone of degenerating minced muscle.

Received Aug. 10, '72. Accepted Feb. 5, '73.

1 Supported by NIH grant 5 t01 GM 00312-10 and funds from Muscular Dystrophy Association of America. The material in this paper is taken from a dissertation submitted in partial fulfillment of the requirements for the degree of Doctor of Philosophy, quirements for the degree of Doctor of Philoso

2 Reported earlier in abstract form (Snow,' 71 ).

3 Present address: Department of Biological structure, University of Miami Medical School, P.O. Box 875, Biscayne Annex, Miami, Florida. 
The significance of this finding is discussed in terms of the success of the regenerative response and of possible relationships with the peripheral regenerating zones.

\section{MATERIALS AND METHODS}

Two hundred and forty one Sprague Dawley rats (Spartan Research Labs, East Lansing, Michigan) of both sexes and 60 to $80 \mathrm{gm}$ were used. The gastrocnemius, plantaris and soleus muscles of the left leg were excised under semi-sterile operative conditions, taking care to preserve the tibial, sural and common peroneal nerves. The muscles were stripped of dense connective tissue, minced into $1 \mathrm{~mm}^{3}$ pieces with small scissors, and a uniform mixture of the minced fragments of all three muscles autotransplanted into the original site. The muscles of the right leg served as the control tissue. For subsequent study the animals were divided into the following groups: (1) normal histological series, (2) vascular injection series, (3) histochemical series, and (4) lactic acid series.

\section{Series I. Normal histology}

Tissues were excised from 21 rats at intervals between 1 and 60 days after the operation. All animals in this and following series were killed by either cervical dislocation or lethal nebutal anesthesia. Entire regenerates were removed, fixed in Bouin's solution, embedded in paraffin, sectioned at $5 \mu$ and stained with hematoxylin and eosin.

\section{Series III. Histochemistry}

Although the pattern of revascularization in early rat regenerates has been recently examined (Carlson, '70a), this series was included in the present study for direct and accurate correlation with the observed metabolic activity. Six animals, sampled at two to eight days after the operation, were anesthetized with sodium pentobarbital, and perfused through the abdominal aorta with Pelikan Ink (Gunther-Wagner, c11/1431a). The regenerating muscle mass was then excised and prepared for light microscopic examination by the same methods as in Series I.

Four animals, at time intervals between four and eight days after the operation, were perfused in a similar manner using Microfil silicone rubber (Canton Biomedical Products, Inc.). The injected silicone was allowed to harden and the soft tissues were subsequently cleared in methyl salicylate. The specimens were examined grossly for evidence of revascularization and were compared with the histological preparations.

\section{Series III. Histochemistry}

One hundred and fifty eight animals were killed between 0 and 100 days after the operation. The regenerating and control tissues were removed and rapidly frozen in a mixture of dry ice and isopentane $\left(-70^{\circ} \mathrm{C}\right)$. Tissues were sectioned at $8-10 \mu$ on an International Equipment Company cryostat, picked up on cover slips and incubated for the following enzymes: cytochrome oxidase for electron transport (Burstone, '61); phosphorylase for glycogen metabolism (Eränkö and Palkama, '61); glucose-6-phosphate dehydrogenase for pentose shunt (Karnovsky and Himmelhoch, '61); lactate dehydrogenase (LDH) for glycolysis (Brody and Engel, '64); succinic dehydrogenase (SDH) for citric acid cycle (Nachlas et al., '57); non-specific esterases for lipid metabolism (Pearse, '60). The specific content and special treatment of the various enzyme incubation media are outlined in table 1 . Controls for the enzyme reactions consisted of serial sections which were heated to $80^{\circ} \mathrm{C}$ for 60 minutes prior to staining. Other control sections were incubated in media with substrates and coenzymes omitted. Dehydrogenase reactions were tested with and without the electron transfer mediator, phenazine methosulfate (PMS). Cytochrome oxidase was controlled by incubating serial sections in the standard media plus sodium cyanide; the absence of staining indicated the specificity of the reaction media for cytochrome oxidase. Neutral lipid was eliminated as an artifact in the diformazan reactions by immersing the sections briefly ( 15 seconds) in $100 \%$ acetone at $4{ }^{\circ} \mathrm{C}$ prior to placing them in the incubation media (Conklin, '66).

Glycogen was demonstrated by the periodic acid-Schiff reaction (Lillie, '65) and compared with adjacent sections in- 
TABLE 1

Incubation media for histochemical reactions on fresh frozen sections. All media made up to $10 \mathrm{ml}$ except cytochrome oxidase and non-specific esterases which were made up to $50 \mathrm{ml}$

\begin{tabular}{|c|c|c|c|c|c|c|c|c|}
\hline Enzyme & Substrate & $\begin{array}{c}\text { Tetrazolium } \\
\text { salt or } \\
\text { coupler }\end{array}$ & Coenzyme & $\begin{array}{l}\text { Electron } \\
\text { mediator }\end{array}$ & Buffer & Inhibitor & $\begin{array}{l}\text { Pre-treatment } \\
\text { of mounted } \\
\text { section }\end{array}$ & $\begin{array}{c}\text { Incubation } \\
\text { time and } \\
\text { temperature }\end{array}$ \\
\hline $\mathrm{CyOx}$ & $\begin{array}{l}\text { N-phenyl- } \\
\text { para-phenyl- } \\
\text { ene-diamine } \\
10 \mathrm{mg}\end{array}$ & $\begin{array}{l}\text { 8-amino- } \\
1,2,3,4- \\
\text { tetra-hydro- } \\
\text { quinolone } \\
10 \mathrm{mg}\end{array}$ & None & None & $\begin{array}{c}0.2 \mathrm{M} \text { Tris } \\
\mathrm{pH} 7.4 \\
15 \mathrm{mI}\end{array}$ & None & None & $\begin{array}{r}45-60^{\prime} \\
25^{\circ} \mathrm{C}\end{array}$ \\
\hline NSE & $\begin{array}{l}\text { Naphthol } \\
\text { AS-D } \\
5 \mathrm{mg}\end{array}$ & $\begin{array}{l}\text { Diazonium } \\
\text { Salt: } \\
\text { Fast Garnet } \\
\text { GBC } \\
40 \mathrm{mg}\end{array}$ & None & None & $\begin{array}{c}0.2 \mathrm{M} \text { Tris } \\
\text { pH } 7.1 \\
10 \mathrm{ml}\end{array}$ & None & $\begin{array}{l}10^{\prime} \text { Fixation } \\
\text { in cold } \\
\text { formo- } \\
\text { calcium }\end{array}$ & $\begin{array}{c}10^{\prime}-40^{\prime} \\
25^{\circ} \mathrm{C}\end{array}$ \\
\hline PHOS & $\begin{array}{c}\text { Glucose 1- } \\
\text { phosphate } \\
50 \mathrm{mg}\end{array}$ & Iodine & None & None & $\begin{array}{r}0.1 \mathrm{M} \\
\text { Acetate } \\
\text { pH } 5.9 \\
6 \mathrm{ml}\end{array}$ & None & None & $\begin{array}{c}30^{\prime}-60^{\prime} \\
37^{\circ} \mathrm{C}\end{array}$ \\
\hline LDH & $\begin{array}{c}0.1 \mathrm{M} \mathrm{D}-\mathrm{L} \\
\text { Lactate } \\
\text { Sodium Salt } \\
3 \mathrm{ml}\end{array}$ & $\begin{array}{r}\text { Nitro B T } \\
5 \text { mg }\end{array}$ & $\begin{array}{l}\text { NAD } \\
3 \mathrm{mg}\end{array}$ & $\begin{array}{c}\text { PMS } \\
0.1 \mathrm{ml}\end{array}$ & $\begin{array}{l}0.2 \mathrm{M} \\
\text { Phosphate } \\
\text { pH } 7.2 \\
6 \mathrm{ml}\end{array}$ & $\begin{array}{l}\text { Sodium } \\
\text { Cyanide } \\
0.06 \mathrm{M} \\
0.75 \mathrm{ml}\end{array}$ & $\begin{array}{l}30 " \text { in cold } \\
\text { formalin } \\
10^{\prime \prime} \text { in } \\
\text { acetone }\end{array}$ & $\begin{array}{c}15^{\prime}-20^{\prime} \\
37^{\circ} \mathrm{C}\end{array}$ \\
\hline SDH & $\begin{array}{l}0.2 \mathrm{M} \text { Sodium } \\
\text { Succinate } \\
2.5 \mathrm{ml}\end{array}$ & $\begin{array}{r}\text { Nitro B T } \\
5 \mathrm{mg}\end{array}$ & None & $\begin{array}{l}\text { PMS } \\
0.1 \text { ml }\end{array}$ & $\begin{array}{l}0.2 \mathrm{M} \\
\text { Phosphate } \\
\text { pH } 7.6\end{array}$ & $\begin{array}{c}\text { Sodium } \\
\text { Cyanide } \\
0.06 \mathrm{M} \\
0.75 \mathrm{ml}\end{array}$ & None & $\begin{array}{c}15^{\prime}-30^{\prime} \\
37^{\circ} \mathrm{C}\end{array}$ \\
\hline G6PDH & $\begin{array}{l}\text { Glucose 6- } \\
\text { phosphate } \\
\text { disodium } \\
134 \mathrm{mg}\end{array}$ & $\begin{array}{r}\text { Nitro B T } \\
5 \text { mg }\end{array}$ & $\begin{array}{l}\text { NADP } \\
3 \mathrm{mg}\end{array}$ & $\begin{array}{c}\text { PMS } \\
0.1 \mathrm{ml}\end{array}$ & $\begin{array}{c}0.2 \mathrm{M} \text { Tris } \\
\text { pH } 7.4 \\
7.0 \mathrm{ml}\end{array}$ & $\begin{array}{c}\text { Sodium } \\
\text { Cyanide } \\
0.06 \mathrm{M} \\
0.75 \mathrm{ml}\end{array}$ & $\begin{array}{l}10^{\prime \prime} \text { Cold } \\
\text { acetone }\end{array}$ & $\begin{array}{c}30^{\prime}-45^{\prime} \\
37^{\circ} \mathrm{C}\end{array}$ \\
\hline
\end{tabular}

cubated for 30 minutes in $1 \%$ alphaamylase prior to the PAS procedure. Oil red o (Lillie, '65) was used to demonstrate neutral lipids.

As an aid in orientation and determining specific cell types in the histochemical material, serial sections cut at the same time were stained with a hematoxylin and eosin procedure adapted for use with frozen sections (Krajian and Gradwohl, '52). Upon completion of the histochemical reactions, the cover slips were inverted on glass slides in glycerol and examined and photographed immediately.

\section{Series IV. Lactic acid determination}

Twenty nine rats were used in this group. The central zone of degenerating muscle was isolated from the surrounding regenerating zone by blunt dissection (see RESUlts for description of zones). This procedure was aided by the difference in color and consistency between the two zones. Large strips of muscle from the contralateral leg served as the control. Wet weights were determined on all tissues which were then placed in ice-cold, stoppered, $25 \mathrm{ml}$ Ehrlenmyer flasks containing phosphate Ringer's solution ( $\mathrm{pH}$ $7.2)$ and sodium cyanide. Glucose, either $1 \mathrm{mg} / \mathrm{ml}$ or $2 \mathrm{mg} / \mathrm{ml}$, was added to each flask immediately prior to incubation. Another control group consisted of tissues incubated without glucose and cyanide. The reaction flasks were then incubated for two hours in a $37^{\circ} \mathrm{C}$ shaker bath after allowing them to equilibrate for the first 15 minutes. Proteins in the $200 \mu \mathrm{l}$ aliquots were precipitated with $10 \%$ trichloracetic acid and all samples were centrifuged for 15 minutes at $\times 10,000 \mathrm{~g}$ in an International micro-capillary centrifuge. The supernatant was assayed for lactic acid according to the colorimetric procedure of Barker and Summerson ("41), as modified by Sippel (personal communication). The 


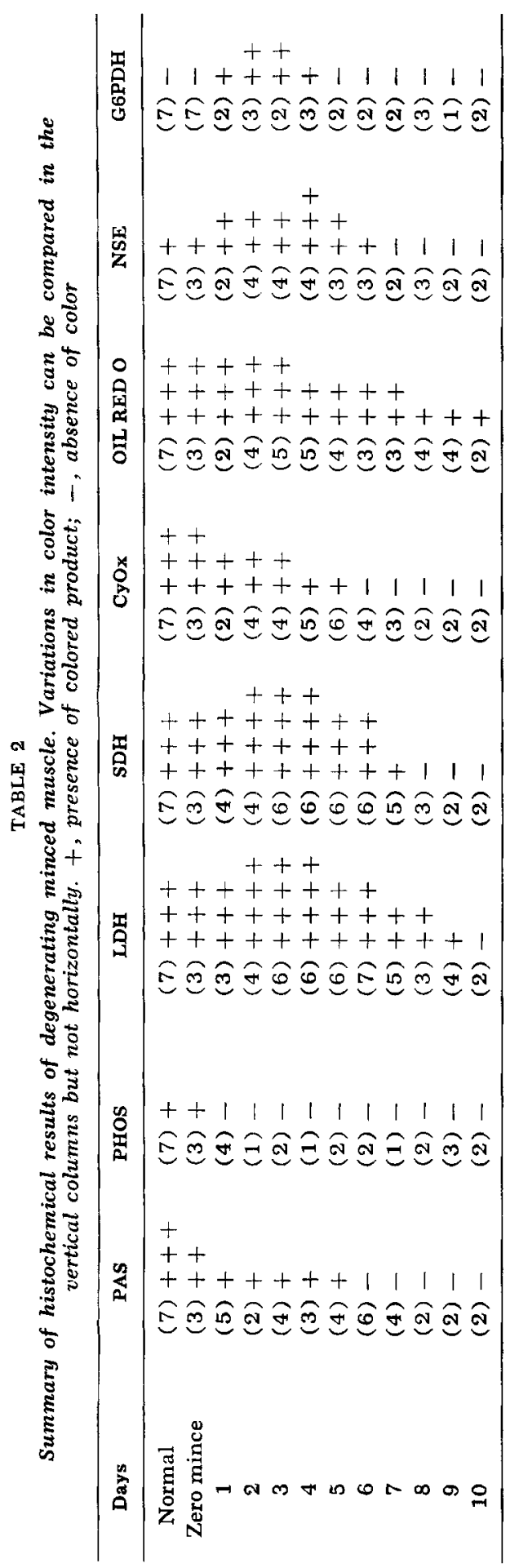

optical density was read at $560 \mathrm{~m}_{\mu}$ on a Bausch and Lomb spectronic 20 colorimeter. Dry weights were determined after incubation by drying all tissues in an $80^{\circ} \mathrm{C}$ oven in the pre-weighed incubation flasks. The flasks and tissues were carefully weighed at 24 hour intervals for five days to determine, as precisely as possible, the dry weight values of the incubated tissues. It was found that the dry weight did not vary after the first 24 hours in the oven. The final calculations for determining tissue activity are based on these dry weights.

\section{RESULTS}

\section{Series 1. Normal histology}

The morphology and normal histological sequence of events for this system have been presented by Carlson ('68, '70a,b). Therefore only a brief description of these processes will be given here.

During the first few days after the operation the minced tissue was characterized by hyaline degeneration of the sarcoplasm and karyolysis of myonuclei. From about days $3-10$, the regenerating mass was distinguished by the presence of three histologically distinct concentrically arranged zones (fig. 2). The innermost zone contained the originally implanted muscle fragments in various stages of hyaline and vacuolar degeneration (fig. 3 ). The second zone was a transitional zone in which the sarcoplasm of the minced muscle was being phagocytized by macrophages with the endomysium remaining intact. Concurrently with the phagocytic process, spindle-shaped mononucleated myoblasts became aligned along the inner surface of the endomysium (fig. 4). These structures, open-ended endomysial tubes with basophilic myoblasts on their inner surface, are referred to as basophilic cuffs. The appearance of basophilic cuffs was the first stage of regeneration which could be demonstrated at the light microscope level. The third zone was the most peripheral and contained regenerating muscle fibers, scar tissue and invading blood vessels. Multinucleated myotubes (also called multinucleated sarcoblasts, multinucleated myoblasts and myosymplasts) were the distinguishing feature of the peripheral zone 
(fig. 5). With time, the peripheral zone gradually expanded as more and more of the degenerating muscle fragments in the central zone were replaced with differentiating myogenic cells. By the ninth or tenth day the central zone had been completely replaced by regenerating muscle and scar tissue. During the second to eighth weeks the new muscle fibers grew in length and diameter as myofilaments and other cellular constituents were synthesized.

\section{Series II. Vascular injections}

Histological examination of regenerates perfused with ink demonstrated that revascularization began at the periphery of the implanted minced muscle within two to three days after mincing. The vessels grew from the periphery toward the center of the implant closely associated with the expanding zone of regenerating muscle. Ink was never seen in the central zone of degenerating muscle, however, by about the ninth day when the central zone had been replaced by regenerating muscle, vessels filled with ink were seen throughout the entire regenerate. This revascularization pattern was confirmed by the appearance of the casts from silicone injections.

\section{Series III. Histochemical results}

Three distinct types of muscle fibers have been described in rat hindlimb muscles based on morphological (Gauthier, '70), histochemical (Stein and Padykula, '62; Edgerton and Simpson, '69; Yellin and Guth, '70; and Guth and Yellin, '71) and physiological (Close, '67) criteria. A "white" (also referred to as Type II, A or $\alpha \beta$ ) fiber, usually largest in diameter has few mitochondria, a narrow $\mathrm{Z}$ line, high glycolytic enzymatic activity, high myosin ATPase activity and is considered a fast contracting fiber. A "red" (Type III, C or a) fiber, usually the smallest in diameter, has many mitochondria, a wide $Z$ line, low glycolytic enzymatic activity, high myosin ATPase activity and has been suggested as being a moderately slow or even fast contracting fiber. The third fiber type (intermediate, Type I, B or $\beta$ ) is intermediate with respect to the above criteria except for having low myosin ATPase activity. The intermediate fiber has recently been suggested as being a slow contracting fiber (Edgerton and Simpson, '69).

Figures 6 through 11 illustrate the histochemical heterogeneity of normal rat skeletal muscle in cross section demonstrated by the techniques used in this

TABLE 3

summary of histochemical results of regenerating minced muscle. Variations in color intensity can be compared in the vertical columns but not horizontally. + , presence of colored product; - absence of color

\begin{tabular}{|c|c|c|c|c|c|c|c|c|}
\hline $\begin{array}{c}\text { Stages of } \\
\text { myogenesis }\end{array}$ & PAS & PHOS & LDH & SDH & CyOx & $\underset{\text { OIL }}{\text { RED }}$ & G6PDH & NSE \\
\hline $\begin{array}{l}\text { Mononucleated cells } \\
\text { lining degenerating } \\
\text { fibers near the } \\
\text { transitional zone }\end{array}$ & - & _- & + & - & - & - & - & - \\
\hline Basophilic cuffs & + & - & ++ & + & - & - & + & - \\
\hline $\begin{array}{l}\text { Myotubes } \\
\text { (no cross- } \\
\text { striations) }\end{array}$ & ++ & - & $++t$ & ++ & + & - & ++ & - \\
\hline $\begin{array}{l}\text { Myotubes } \\
\text { (with cross- } \\
\text { striations) }\end{array}$ & +++ & + & +++ & ++ & ++ & - & + & - \\
\hline $\begin{array}{l}\text { Myofibers } \\
\quad(14-21 \text { days })\end{array}$ & +++ & ++ & ++ & ++ & ++ & - & - & - \\
\hline $\begin{array}{l}\text { Myofibers } \\
\text { (22 days-maturity) }\end{array}$ & ++++ & +++ & +++ & +++ & $++t$ & - & - & - \\
\hline
\end{tabular}


study. The small red fibers tended to stain intensely for oxidative enzymes and neutral lipids (figs. $6,7,8,9$ ), while the larger white fibers stained heavily for glycolytic enzymes and glycogen (figs. $7,10,11$ ). Glucose-6-phosphate dehydrogenase and non-specific esterases were not detected in normal rat muscle except for some esterase activity associated with end-plates.

Immediately after mincing, the muscle fragments in the central zone of 0 to 10 day regenerates showed normal histochemical reactions except for a slight reduction in PAS positive material. Within the first 24 hours a marked reduction in intracellular PAS staining was seen (fig. 12). Also evident at this time was the disappearance of the phosphorylase-linked staining reaction in all minced muscle fibers. Lactate dehydrogenase and succinic dehydrogenase-linked staining remained relatively normal during the first few days following the operation. Between the second and fourth days a slight increase in staining intensity for both LDH and $\mathrm{SDH}$ (fig. 13) reactions was observed within the degenerating fibers of the central zone. This interpretation was based on two observations: (1) examination of a large population of degenerating fibers revealed an absence of typical white fibers (i.e., large diameter fibers which stain weakly for SDH activity), and instead, large diameter fibers intensely stained for SDH activity were noted, and (2) intracellular diformazan granules of all degenerating fibers appeared larger than normal. Beginning on about the fourth day the $\mathrm{LDH}$ and $\mathrm{SDH}$ activities as indicated by the amount of final reaction product, steadily diminished until LDH disappeared by the ninth day and SDH by the seventh day. The last degenerating fibers to display $\mathrm{SDH}$ activity were located in the very center of the central zone. Both SDH and $\mathrm{LDH}$ staining reactions were extracellular, as well as intracellular, in the degenerating zone, but when adjacent sections were rinsed in acetone prior to incubation the staining product was seen only intracellularly. Since acetone removes neutral lipid, the extracellular material in non-acetone treated sections was probably neutral lipid which had absorbed diformazan precipitate. This was supported by oil red $O$ stained sections which showed extracelluIar neutral lipid. The significance of the extracellular staining has not been determined at this time, but it may be related to degenerative processes and changes in membrane permeability. Cytochrome oxidase staining usually disappeared in the central zone of degenerating muscle within four days after mincing. Glucose-6phosphate dehydrogenase, although not demonstrable in normal muscle, was weakly reactive in the muscle fibers of the central zone from days 2 to 5 . The histochemical reaction for non-specific esterases demonstrated a colored end-product which was homogeneously distributed throughout the degenerating myofibers of the central zone (fig. 14). This final reaction product was more abundant than that associated with motor end-plates of normal muscle.

Glycogen granules were rarely detected in developing muscle prior to the multinucleated myotube stage. Regenerating fibers from the second week to maturity were characterized by heterogeneous PAS staining when examined in cross section (fig. 15). This appeared to be an indication of uneven glycogen storage rather than of different fiber types, because a single fiber in longitudinal section also showed heterogenous staining. The activity of phosphorylase was first seen in myotubes in the regenerating zone of eight to ten day regenerates. The product of the enzyme reaction was weakly localized in the sarcoplasm in a reticulated pattern. The intensity of staining steadily increased during the next 10 to 15 days, but there was no indication of different fiber types at this time (fig. 16). In the transitional zone, myoblasts were moderately reactive for lactate dehydrogenase (fig. 17). As differentiation progresses, LDH activity appeared to increase, as demonstrated by the intense staining reaction seen in multinucleated myotubes located in the peripheral regenerating zone (fig. 18). A reticulated pattern of diformazan precipitation was seen in cross sections of fibers from the second week to maturity when incubated for $\mathrm{LDH}$ activity. Two additional characteristics which were evident during the second and third week of the LDH reaction were heavy subsarcolemmal deposits 
of diformazan, and an occasional dark precipitate of dye in the center of the fiber. Weakly reactive succinic dehydrogenase in basophilic cuffs was more prominent in multinucleated myotubes (fig. 19). The staining pattern in the myotubes tended to be perinuclear. The staining pattern for $\mathrm{SDH}$ in more mature regenerating fibers was similar to that seen in sections incubated for LDH activity. The appearance and localization of cytochrome oxidase activity was very similar to that of SDH and LDH. Glucose-6-phosphate dehydrogenase was weakly reactive in basophilic cuffs and became moderately reactive in more mature myotubes. This pentose shunt enzyme could not be demonstrated in regenerating muscle after the second week using the current techniques. Neutral lipid and non-specific esterases were not detected in regenerating muscle fibers during the first month.

\section{Series IV. Lactic acid determination}

The capacity for anaerobic metabolism was examined in the degenerating muscle

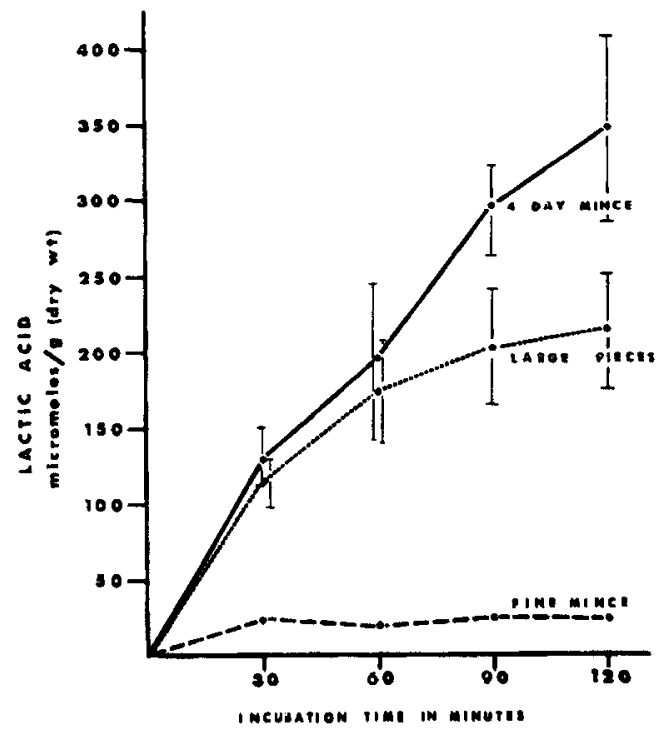

Fig. 1 Comparison of lactic acid produced by minced muscle ( 4 day mince) isolated from central zone of four day regenerates and the two control groups (large pieces and fine mince). Each point represents the mean of six to eight animals, and the vertical bars represent standard deviation. of four day regenerates by analyzing the production of lactic acid in vitro. The results shown in figure 1 illustrate that $2 \mathrm{~mm} \times 3 \mathrm{~mm} \times 6 \mathrm{~mm}$ pieces (large pieces) of normal muscle produced lactic acid. It is also shown in this figure that when normal muscle was minced into $1 \mathrm{~mm}^{3}$ pieces (fine mince) the production of lactic acid was significantly reduced as compared to the larger pieces. When degenerating muscle isolated from four day regenerates was incubated in vitro in the presence of glucose, it produced lactic acid at an initial rate similar to the large pieces of normal muscle (fig. 1). It was noted that between the first and second hours of incubation there was a greater output of lactic acid by the four day degenerating muscle compared with the large pieces of normal muscle.

When the central zone of degenerating tissue from four day regenerates was incubated without glucose, no lactic acid was formed.

\section{DISCUSSION}

\section{Degenerating muscle}

The present histochemical observations show an absence of glycogen and phosphorylase activity by 12 hours after the muscle is minced. The results are in agreement with those of several investigators studying glycogen metabolism in injured amphibian muscle (Schmidt, '60; Wolfe and Cohen, '63) and mammalian muscle (Dampel', '61, '65; Smith, '65; Kuc, '69; Reznik and Engel, '70). This initial disappearance of glycogen probably reflects anaerobic metabolism of this substrate to lactic acid since the blood supply to the injured muscle is completely interrupted during the operation. In this experimental system the absence of vascular components in the central zone of degenerating muscle could explain why glycogen is not seen in this region after depletion of the original carbohydrate stores. Without a vascular system, glucose has no way of reaching the central zone other than by diffusion. If diffusion were adequate to supply glucose, then the absence of glycogen staining would have to be attributed to inactivation of enzymes and cofactors necessary for glycogen biosynthesis, shunting of glycogen precursors into the Emden- 
Meyerhof pathway, or utilization of glycogen as soon as it is synthesized.

Even though glycogen is depleted in the central zone, a positive histochemical reaction for lactate dehydrogenase activity persists until the second week, suggesting that an anaerobic pathway remains operative in the degenerating muscle. It is important to stress that wherever this activity is seen it is homogeneous throughout the injured muscle fiber and is not restricted to the periphery of the fiber. These results are in agreement with other histochemical investigations of LDH activity in injured muscle (Schmidt and Weidman, '64; Johnson and Singer '64). Further evidence for the persistence of anaerobic metabolism in the central zone is provided in in vitro experiments which show that lactic acid is produced by this tissue when it is incubated with glucose and cyanide. While the histochemical results indicate only one step in the glycolitic pathway, the lactic acid results indicate that the entire pathway is intact.

It should be emphasized that the central zone tissue does not produce lactic acid when glucose is omitted from the incubation media. This suggests that glycolytic substrates are not produced within the central zone. Therefore, it seems most likely that any glycolytic activity in the central zone in vivo would be dependent on the availability of substrate from the surrounding vascularized regions.

At present, the significance of the anaerobic metabolic activity in the central zone is not fully understood. Further experimentation is necessary in order to determine which cells are responsible for the activity, and to determine to what extent the success of the regenerative response is dependent on this metabolism. It is possible that the chemical energy produced during glycolysis is used in a regenerative capacity associated with the formation and maintenance of myogenic cells. It is also possible that the ATP provides the necessary energy for synthesis of degradative enzymes in the central zone.

The observed metabolism after mincing supports the plastic state theory proposed by Studitsky et al. ('56) which maintains that skeletal muscle has the capacity to be transformed, when minced, into a state characterized by an increase in cytoplasmic RNA and a change from aerobic to anaerobic metabolism. Studitsky postulated that it is this plastic state which maintains the minced tissue for as long as seven to ten days until the regenerative process begins.

The positive histochemical staining for the glucose-6-phosphate dehydrogenase procedure in the central zone indicates pentose shunt activity which produces one of the necessary metabolites in nucleic acid synthesis, pentose phostphate. This observation correlates with autoradiographic studies showing incorporation of ${ }^{3} \mathrm{H}$-thymidine and ${ }^{3} \mathrm{H}$-uridine in the central zone of minced amphibian muscle (Carlson, '70b), and it provides further evidence that the central zone is biosynthetically active.

With respect to aerobic metabolism, the apparent increase in SDH activity is in agreement with observations by Schmidt and Weidman ('64), Johnson and Singer ('64) and Smith ('65) on other systems involving muscle injury. Morphological support for the increase in SDH activity has been provided by Resnik and Hansen ('69) and Reznik and Engel ('70) in ultrastructural studies of cold-injured mammalian muscle. They demonstrated an increase in size and number of mitochondria in the muscle fibers located adjacent to the necrotic tissue. Trupin (personal communication), on the other hand, has observed an increase in size but no change in number of mitochondria in a fine structural study of amphibian minced muscle regeneration.

It is impossible to conclude on the basis of the reported experiments whether or not aerobic metabolism is active in the central zone of early regenerates. Succinic dehydrogenase activity seemed to increase briefly, while cytochrome oxidase activity rapidly disappeared. Further studies, such as additional enzymatic analyses, examination of the ultrastructural status of the mitochondria, and determinations of the capacity for gaseous exchange, would provide valuable information concerning the metabolic state of the degenerating muscle.

\section{Regenerating muscle}

Glycogen metabolism does not appear to 
play a significant role in the early stages of muscle differentiation since glycogen and phosphorylase can not be detected histochemically until after cross-striations are demonstrable at the light microscopic level. The absence of glycogen granules in myoblasts is supported by the ultrastructural work of Lentz ('69) and Trupin (personal communication) who examined regenerating newt and frog muscle respectively.

Evidence for active glycolytic pathways during early myoblast development is provided by the histochemical demonstration of $\mathrm{LDH}$ activity in the regenerating cells of basophilic cuffs. In addition, $\mathrm{LDH}$ activity at the periphery of degenerating muscle fragments, which have not shown signs of phagocytosis, suggests glycolytic activity at an even earlier stage of development that the basophilic cuff cells. Since stored glycogen does not seem to be present in myoblasts, it is possible that glucose is transported from adjacent blood vessels into the regenerating cells for use in glycolysis.

Aerobic metabolism does not seem to be a major source of energy in myoblast differentiation. Histochemical data reported above are in agreement with several electron microscopic studies which show only a few mitochondria in myoblasts (Lentz, '69; Turpin, personal communication; Hay, '59; Reznik, '69; Shafiq and Gorycki, '65). Since SDH and cytochrome oxidase are shown to be very active during later stages of muscle regeneration, it is assumed that the cellular machinery necessary for aerobic metabolism is in the process of being developed during the myoblast stage.

Another active metabolic pathway in the early stages of regeneration is the pentose shunt. This observation agrees with the histochemical studies of amphibian (Schmidt and Weidman, '64; Wolfe and Cohen, '63) and mammalian muscle regeneration (Smith, '65). It has been shown that the pentose shunt produces ribose-5-phosphate necessary for nucleic acid synthesis. Thus, reports on RNA synthesis during myoblast and myotube differentiation (Bodemer, '62; Carlson, '70b) correlate with the presence of glucose-6-phosphate dehydrogenase activity seen at the same time period in the present investigation.

The pattern of revascularization as demonstrated by ink perfusions correlates well with the metabolic activity seen qualitatively. Blood vessels filled with ink are never seen in the central zone, but they are always observed in the transitional zone as it progresses toward the center. Thus, any active energy producing mechanisms in the central region might be expected to be limited to anaerobic metabolism. This is confirmed by the evidence that the capacity for glycolytic activity is retained in the central zone. It is possible that glycolysis produces the energy necessary to maintain presumptive myoblasts in the central zone until they are reached by ingrowing capillaries, at which time phagocytosis of the old sarcoplasm begins and myoblast fusion occurs.

\section{ACKNOWLEDGMENTS}

I would like to express my sincere appreciation to Dr. Bruce M. Carlson for his guidance during this investigation, and to Dr. Richard L. Wood for his assistance with the manuscript.

\section{LITERATURE CITED}

Barker, S. B., and W. H. Summerson 1941 The colorimetric determination of lactic acid in biological material. J. Biol. Chem., 138: 535554.

Betz, E. H., H. Firket and M. Reznik 1966 Some aspects of muscle regeneration. Int. Rev. Cytol., 19: 203-227.

Bodemer, C. W. 1962 Distribution of ribonucleic acid on the urodele limb as determined by radioautographic localization of uridine- $\mathrm{H}^{3}$. Anat. Rec., 142: 457-468.

Brody, I. A., and W. K. Engel 1964 Effects of phenazine methosulphate in histochemistry. J. Histochem. Cytochem., 12: 928-929.

Burstone, M. S. 1961 Modification of histochemical techniques for the demonstration of cytochrome oxidase. J. Histochem. Cytochem., 9: 59-92.

Carlson, B. M. 1968 Regeneration of the completely excised gastrocnemius muscle in the frog and rat from minced muscle fragments. J. Morph., 125: 447-472.

- 1970a The regeneration of entire muscles from minced fragments. In: Regeneration of Striated Muscle, and Myogenesis. A Mauro, S. A. Shafiq and A. T. Milhorat, eds. Excerpta Medica, Amsterdam, pp. 25-37.

- 1970b Histological observations on the regeneration of mammalian and amphibian muscle. In: Regeneration of Striated Muscle, and Myogenesis. A. Mauro, S. A. Shafiq and 
A. T. Milhorat, eds. Excerpta Medica, Amster. dam, pp. 38-72.

1972 The Regeneration of Minced Muscles. Karger, Basel.

Church, J. C. T., R. F. X. Noronka and D. B. Allbrook 1966 Satellite cells and skeletal muscle regeneration. Brit. J. Surg., 53: 638-642.

Close, R. 1967 Properties of motor units in fast and slow skeletal muscles of the rat. J. Physiol., 193: 45-55.

Conklin, J. E. 1966 Histochemical localization of enzymes in the embryonic chick liver. J. Exp. Zool., 161: 251-270.

Dampel', N. W. 1961 The dynamics of the dis. tribution of glycogen in regenerating skeletal muscle during the period of early post em. bryonal development in rats. (Russian) Arkh. Anat., 40: 54-59.

- 1965 Distribution of nucleic acid in regenerating skeletal tissues during postembryonic rat development. (Russian) Arkh. Anat., 49: 49-99.

Edgerton, V. R., and D. R. Simpson 1969 The intermediate muscle fiber of rats and guinea pigs. J. Histochem. Cytochem, 17; 828-838.

Eränkö, O., and Palkama 1961 Improved localization of phosphorylase by the use of polyvinyl pyrolidone and high substrate concentration. J. Histochem. Cytochem., 9: 585.

Field, E. J. 1960 Muscle regeneration and repair. In: Structure and Function of Muscle. III. G. H. Bourne, ed. Academic Press, N. Y., pp. 139-170.

Gauthier, G. F. 1970 The ultrastructure of three fiber types in mammalian skeletal muscle. In: The Physiology and Biochemistry of Muscle as a Food, 2. E. J. Birisky, R. G. Cassens, and B. B. Marsh, eds. Univ. of Wisconsin Press, Madison, Wisconsin, pp. 103-130.

Guth, L., and H. Yellin 1971 The dynamic nature of the so-called "fiber types" of mammalian skeletal muscle. Exp. Neurol., 31: 277300.

Hay, E. 1959 Electron microscopic observations of muscle dedifferentiation in regenerating Amblystoma limbs. Develop. Biol., 1: 555585.

Johnson, E., and M. Singer 1964 A histochemical study of succinic dehydrogenase and lactate dehydrogenase in the regenerating forelimb of the adult newt, Triturus. Proc. Soc. Exp. Biol. Med., 117: 27-31.

Karnovsky, M. J., and S. R. Himmelhoch 1961 The use of ethylene diamine tetra acetic acid disodium in the histochemical demonstration of triphosphopyridine nucleotide-linked dehydrogenases. J, Histochem. Cytochem., 9: 203204.

Krajian, A. A., and R. B. H. Gradwohl 1952 Histopatholigical Technique. Second ed. C. V. Mosby Co., New York, pp. 81-82.

Kuc, A. 1969 Morphologic and histolochemical studies on the regeneration of striated muscles in the white rat. Folia Morph. (Warsaw), 28: 17-26.

Lentz, T. L. 1969 Cytological studies of muscle dedifferentiation and differentiation during limb regeneration of the newt Triturus. Am. J Anat., 124: 447-479.

Lillie, R. D. 1965 Histopathologic Techniques and Practical Histochemistry. McGraw-Hill Book Co., New York.

Mauro, A. 1961 Satellite cell of skeletal muscle fibers. J. Biophys. Biochem. Cytol., 9: 493-495.

Nachlas, M. T., T. Kwan-Chung, E. DeSouza, C. Cheng and A. Seligman 1957 Cytochemical demonstration of succinic dehydrogenase by the use of a new p-nitro-phenyl substituted ditetrazole. J. Histochem. Cytochem., 5: 420436.

Nachlas, M. M., S. I. Margilies and A. M. Seligman 1960 A colorimetric method for the estimation of succinic dehydrogenase activity. J. Biol. Chem., 234: 499-509.

Pearse, A. G. E. 1960 Histochemistry. Theoret ical and Applied. Second ed. Little, Brown, Boston, pp. 887-888.

Reznik, M. 1969 Origin of myoblasts during skeletal muscle regeneration. Electron microscopic observations. Lab. Invest., 20: 353-363.

Reznik, M., and W. K. Engel 1970 Ultrastructural and histochemical correlations of experimental muscle regeneration. J. Neurol. Sci., 11: 167-185.

Reznik, M., and J. L. Hansen 1969 Mitochondria in degenerating and regenerating skeletal muscle. Arch. Path., 87: 601-608.

Schmidt, A. J. 1960 Preblastemic changes in intramusculax glycogen in forelimb regeneration of the adult newt, Triturus viridescens. J. Exp. Zool., 145: 43-48.

1968 Cellular Biology of Vertebrate Regeneration and Repair. University of Chicago Press, Chicago, pp. 33-37.

Schmidt, A. J., and T. Weidman 1964 Dehydrogenases and aldolase in the regenerating forelimb of the adult newt, Diemictylus viridescens. J. Exp. Zool., 155: 303-316.

Shafiq, S. A., and M. A. Gorycki 1965 Regeneration in skeletal muscles of the mouse: Some electron microscopic observations. J. Path. Bact, 90: 123-127.

Smith, B. 1965 Histochemical changes in necrosis and regeneration. J. Path. Bact., 89 : 139-143.

Snow, M. H. 1971 Glycolysis in degenerating skeletal muscle isolated from early minced muscle regenerates in the rat. Anat. Rec., 169: 433-434.

Stein, J., and H. A. Padykula 1962 Hístochemical classification of individual skeletal muscle fibers of the rat. Am. J. Anat., 110: 103-123.

Studitsky, A. N., R. P. Zhenevskaya and O. N. Rumyantseva 1956 Fundamentals of the technique of restoration of muscle by means of transplantation of minced muscular tissue (Russian). Cesk. Morfol., 4: 331-340.

Wolfe, H. J., and R. B. Cohen 1963 Histochemical studies on the regenerating urodele limb. I. Oxidative and glycolytic enzymes. Develop. Biol., 48; 48-66.

Yellin, H., and L. Guth 1970 The histochemical classification of muscle fibers. Exp. Neurol. 26: $424-431$. 
PLATES 


\section{PLATE 1}

EXPLANATION OF FIGURES

2 Hematoxylin and eosin stained section of a five day regenerate, showing a central (C) zone of degenerating muscle, transitional ( $T$ ) zone and a peripheral (P) zone of regenerating muscle. $\times 60$.

3 A higher power view of the central zone in figure 2. Note the sparsity of nuclei associated with the muscle fibers and the hyalinized state of the sarcoplasm. Hematoxylin and eosin. $\times 300$.

4 A higher power view of the transitional zone of figure 2. The arrows point to basophilic cuffs which are lines by myoblasts or early myotubes. The sarcoplasm inside the cuffs is being removed by phagocytes. Stained with hematoxylin and eosin. $\times 300$.

5 A higher power view of the peripheral zone in figure 2, showing multinucleated myotubes (arrows) with large nuclei and prominent nucleoli. The background tissue is newly forming connective tissue. Stained with hematoxylin and eosin. $\times 300$. 


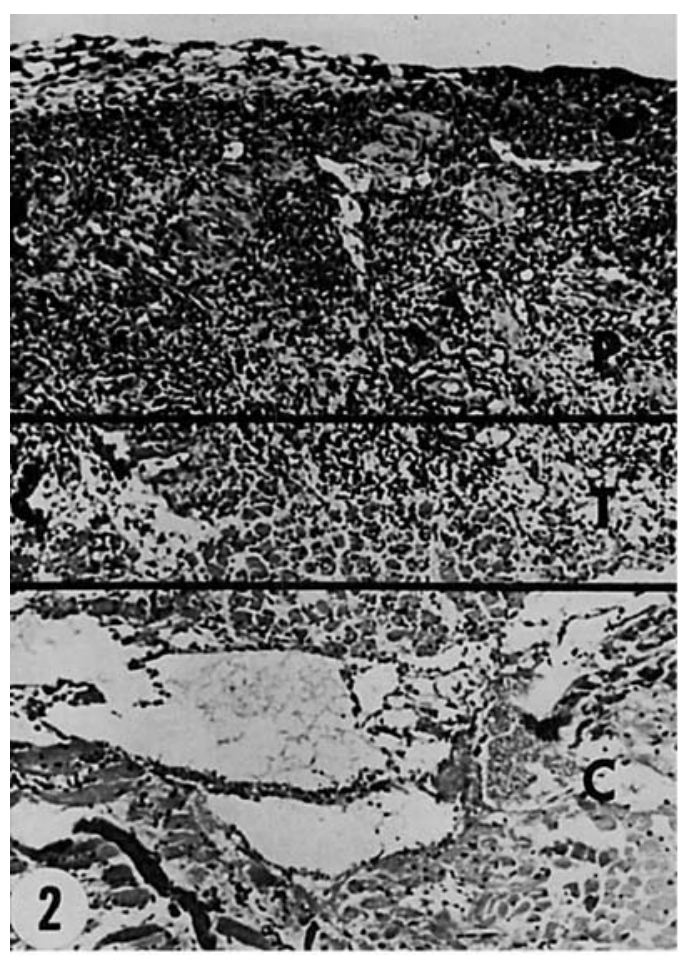

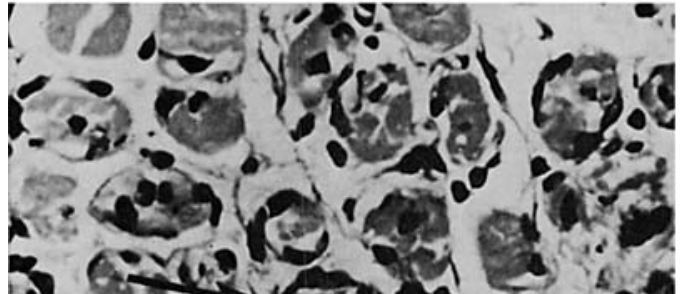

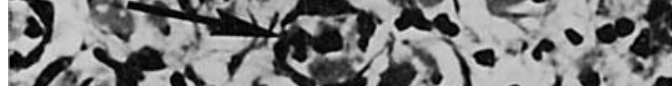

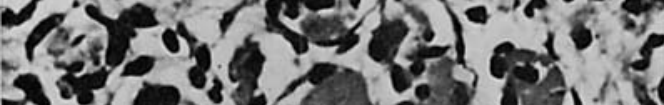
30 as

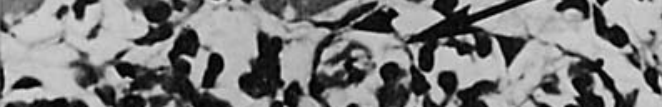

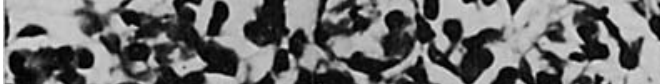

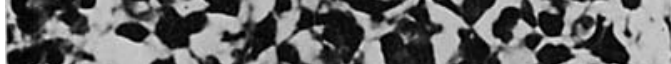

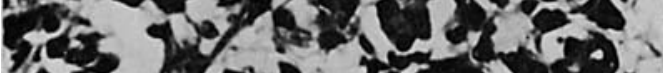

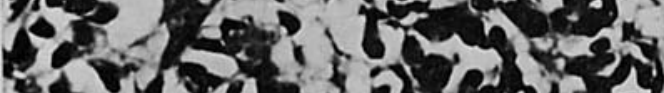

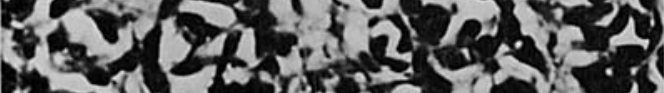

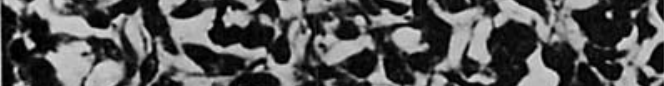
1.

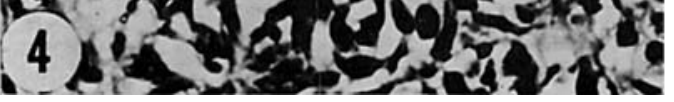

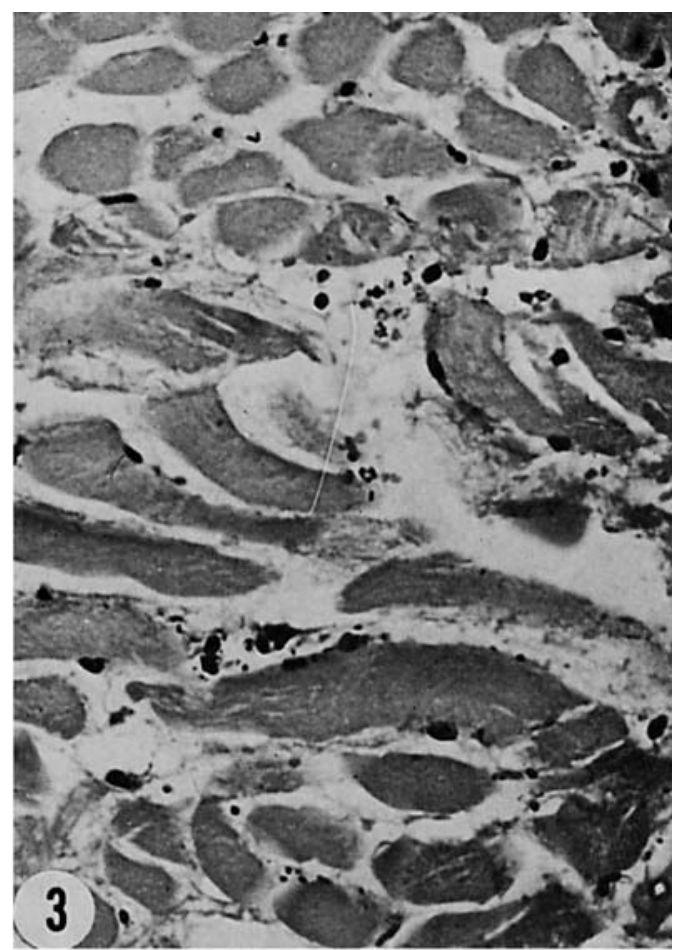

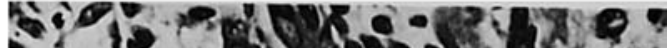
th 13 a

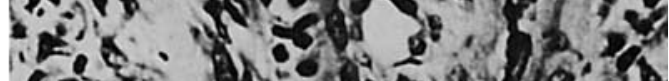

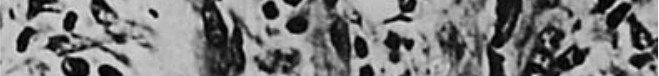

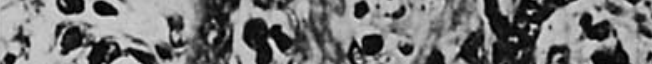

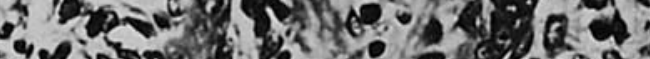

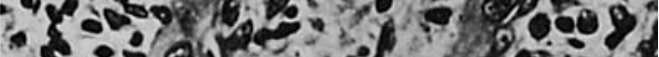

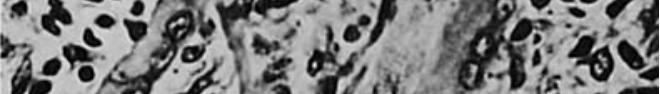

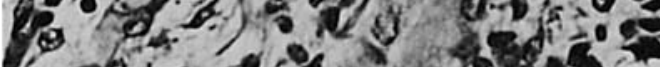

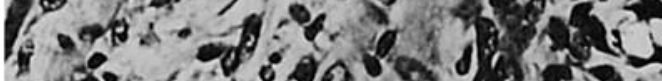
R3.

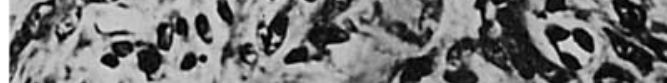

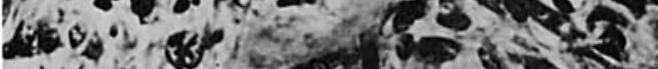
if 7 , ans 1)

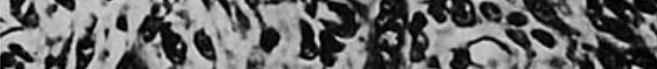
Cark

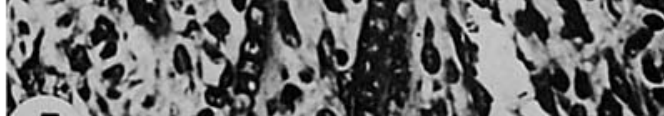

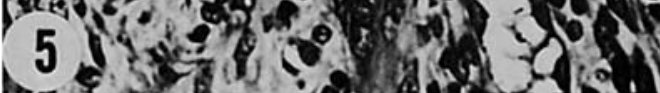


PLATE 2

EXPLANATION OF FIGURES

6 Normal muscle stained for succinic dehydrogenase. Note the small diameter heavily stained red fibers, the somewhat larger and less densely stained intermediate fibers and the very large, weakly stained white fibers. $\times 320$.

7 Normal muscle stained for lactate dehydrogenase. The small diameter fibers are slightly darker than the larger fibers. $\times 320$.

8 Normal muscle stained for cytochrome oxidase. The small diameter fibers are more darkly stained. $\times 320$.

9 Normal muscle stained for neutral lipids with the oil red O procedure. The small diameter fibers contain more lipid droplets than the large diameter fibers, $\times 320$.

10 Normal muscle stained for phosphorylase. The larger diameter fibers are more darkly stained. $\times 320$.

11 Normal muscle stained with PAS. There is heterogeneous staining, but no correlation with fiber diameter. $\times 320$. 

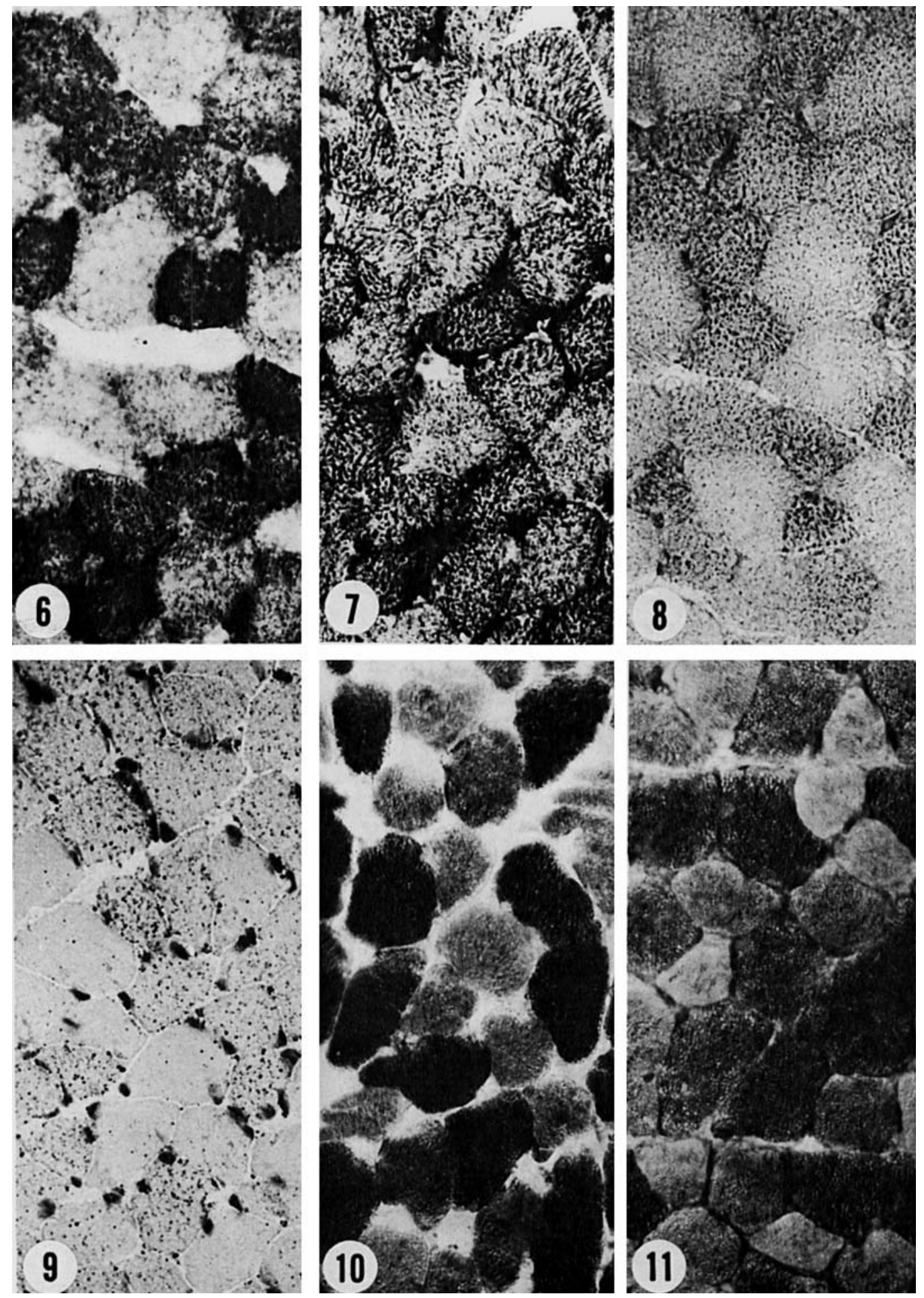


\section{PLATE 3}

EXPLANATION OF FIGURES

12 A section of a one day minced muscle implant stained with PAS, demonstrating the marked reduction in intracellular glycogen (compare to fig. 11 for normal glycogen distribution). The PAS positive granules in the sarcoplasm are glycogen deposits which disappear in older regenerates. $\times 320$.

13 A section of a three day regenerate, central zone, stained for succinic dehydrogenase. Note the overall dense staining with little indication of a checkerboard pattern. The intracellular diformazan granules appear larger than normal, and there is heavy subsarcolemmal staining. $\times 320$.

14 A section of the central zone of a two day regenerate stained for non-specific esterases. Many fibers are positively stained while normal muscle is negative except for motor end-plate regions. $\times 125$.

15 Cross-section of a 12 day regenerate stained with PAS. This demonstrates the heterogeneous staining for glycogen. $\times 125$. 
Mikel H. Snow
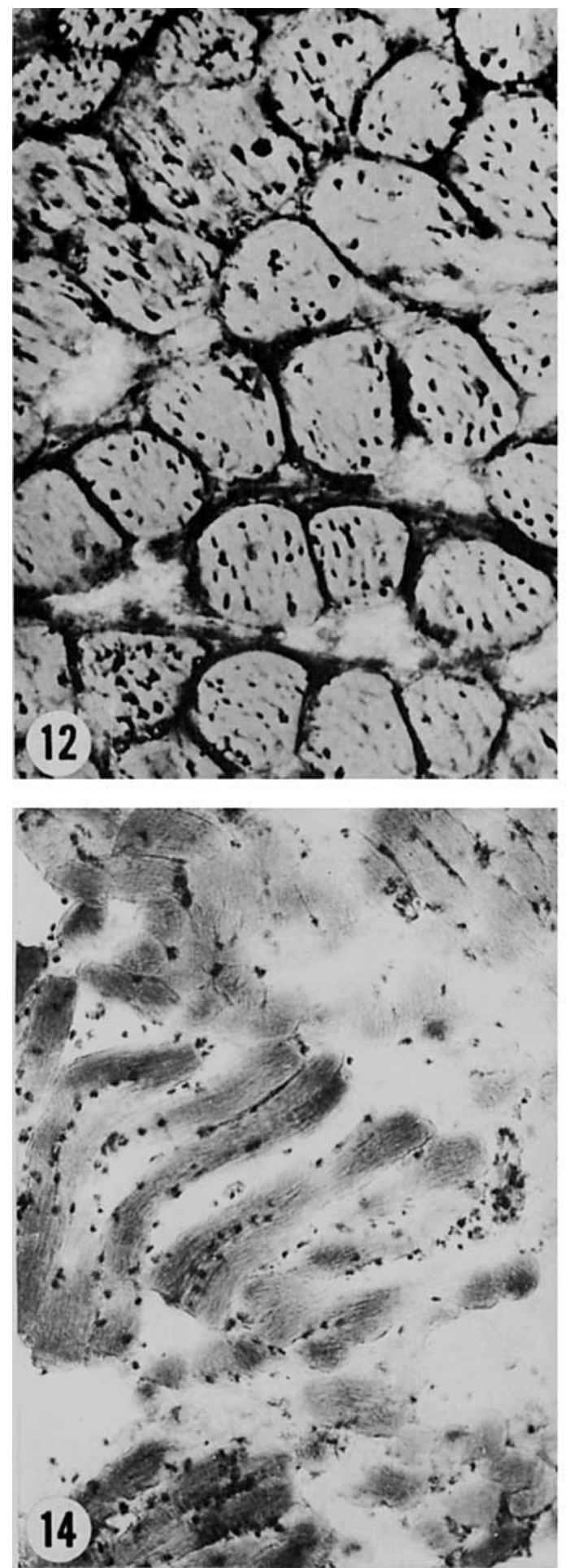
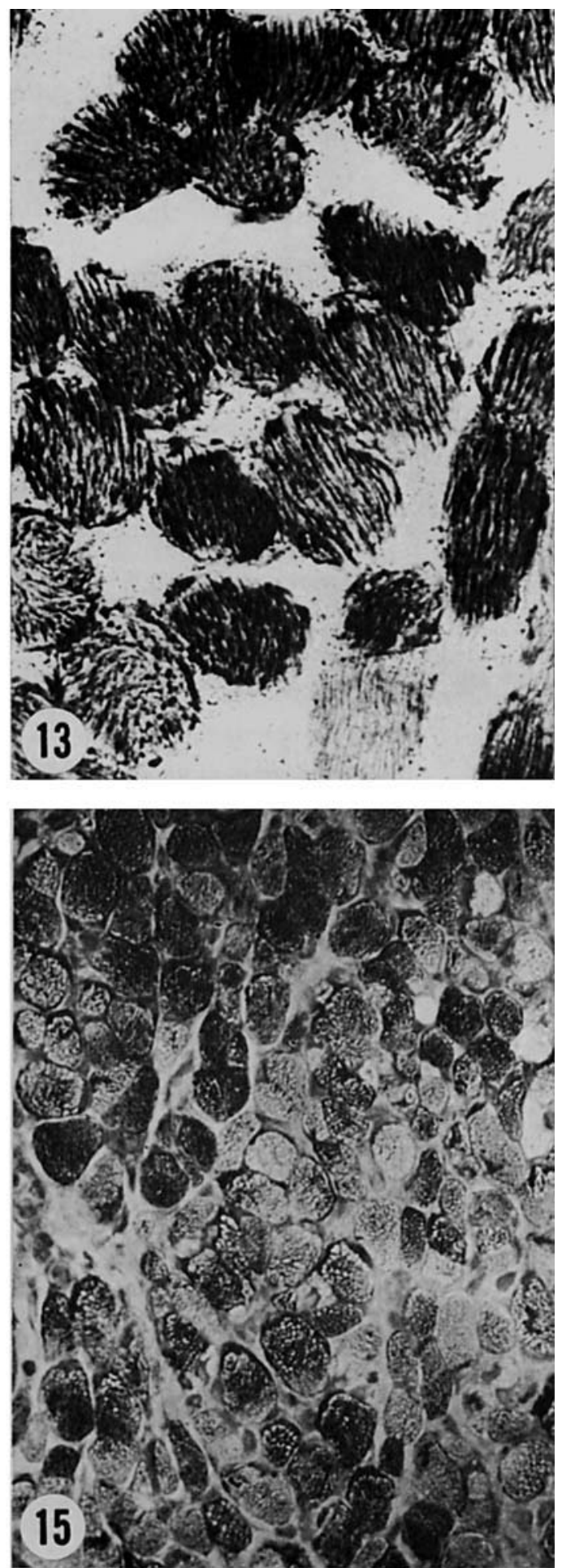
PLATE 4

EXPLANATION OF FIGURES

16 Cross-section of a ten day regenerate stained for phosphorylase. The staining pattern is homogeneous. $\times 320$.

17 Transitional zone of a three day regenerate. This section is stained for LDH showing dark staining at the periphery of degenerating myofibers in which the old sarcoplasm has not yet been phagocytized. The darkly stained cells (arrows) are interpreted as myoblasts although definitive confirmation can not be made at the light microscopic level at this stage. $\times 125$.

18 Regenerating peripheral zone of a six day regenerate. Multinucleated myotubes are shown heavily stained for LDH. $\times 320$.

19 Longitudinal section of myotubes from a six day regenerate. These cells have heavy deposits of diformazan from SDH activity. $\times 320$. 

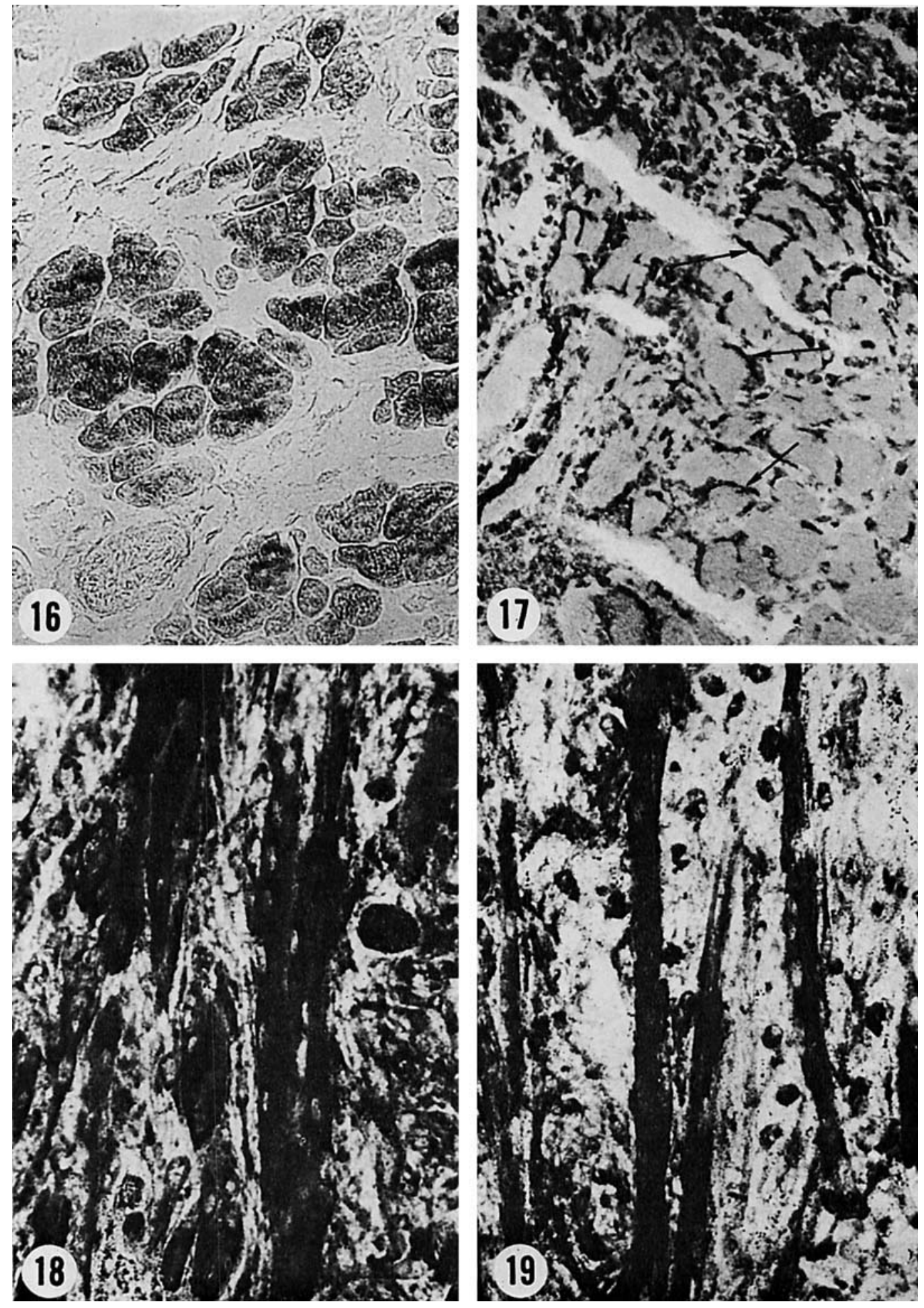